\title{
An Investigation of Beliefs, Information and the Halo Effect in Electoral Decision Making
}

\author{
Ishan Kashyap Hazarika ${ }^{1}$ and Sourabh Rai ${ }^{2}$ \\ ${ }^{1 \& 2}$ Student, Department of Economics, Hansraj College, University of Delhi, India \\ E-mail: kpishanh@gmail.com
}

\begin{abstract}
Rational ignorance suggests that voters largely ignore a lot of information while voting due to the high cost of attaining and processing the information. It is further suggested that rational voters do not vote to affect election results but to express opinions. It is thus likely that cognitive biases shape electoral decision-making. The Halo effect, for instance, extrapolates information in one domain to another and helps voters avoid processing extra information. In this paper, we investigate the conditions under which extra information is processed or ignored, and first impressions are generalised. We find, through a Randomised Control Experiment, that new and weakly formed political beliefs also have effects like strongly held political beliefs, on information provided later. In particular, the study presented pictureinformation about candidates, either accompanying or not accompanying text-information. Additional text-information did not significantly change voter-choice when the text information reaffirmed picture-based preferences but did significantly change voter-choice when it contradicted picturebased preferences. These results are viewed from the perspective of both the Identity-Protective Cognition Thesis and the Halo effect, thus hinting that the two may be connected, an insight that is largely missing in the previous literature.
\end{abstract}

Keywords: Halo effect, Identity-Protective Cognition Thesis (ICT), Rational ignorance, Randomized Control Experiments.

\section{INTRODUCTION}

The relevance of cognitive biases in explaining human behaviour is being recognized in recent times in economics. Similar biases, undoubtedly play an important role in other manifestations of human behaviour too, such as political decision-making. At the same time, the role of information can also be scrutinized in the voter's decision problem. A first glance immediately relates it to the idea of 'rational ignorance', where the voters ignore relevant information when making voting decisions as the cost of processing the information is high and the expected benefits, due to the usually large size of the electorate, low. The interplay becomes even more interesting, as the same cost-benefit argument is used by Downs (1957) to argue that rational decision-makers would exhibit extremely low voter turnouts (contrary to what is practically observed) in the famous Voter's Paradox. This has prompted many to conclude that voting is done not to influence election outcomes, but as a tribal ritual to show support or other emotional benefits. This brings us back to the domain of cognitive biases and psychological effects from yet another direction.

In this paper, we investigate one such bias in the realm of electoral decision-making by voters- the Halo effect. The Halo effect can be defined as "the tendency of an opinion created in one area to influence opinion in another area". For example, views such as "a successful sportsperson would also be good at relationships", or "a veteran is likely to be a good leader too" etc. can be argued to follow from the Halo effect. The tendency of the first impression having a lasting impact can also be explained using this cognitive bias.

A presence of this bias in electoral decision making is already established. Several studies have found empirical support for its presence using econometric as well as psychometric techniques. The presence of the effect has also been related to and studied vis-a-vis personality traits. In this paper, we attempt to explore a hitherto largely unexplored area of how the effect interacts with information.

The study of cognitive biases and psychological effects as an explanation of electoral behaviour in contrast to information effect as usually studied in the rational choice framework is common, but the study of both as influencing each other and interacting is as of now relatively left out. In this paper, we seek to at least partly to fill this gap in research. Electoral behaviour can be studied from realworld data as has been done many times. But to accomplish the task, we use the method of Randomized Control Experiments, as it serves well to isolate the Halo effect and the effect of information on decision-making in the surveyed population.

\section{LITERATURE REVIEW}

An early discussion of the Halo effect can be found in Nisbett and Wilson (1977). Several studies have since then extended and applied this idea. The effect of various 
attributes of a person on perceived political qualities, such as competence, trustworthiness etc. has been studied.

In particular, the manifestation of the Halo effect as the "attractiveness stereotype" (Thorndike,1920), where physical attractiveness may influence the impression of other qualities, which we use in this paper has been studied before. Several studies have found the existence of this effect in political settings (Atkinson et al., 2009; Surawski and Ossof,2006; Berggren et al.,2010; Lenz et al., 2011). The existence of this effect is especially noticeable in rating-data. (Kozlowski et al., 1986).

Research in political science has established the existence of positive effects of attractiveness and perceived competence on electoral success (Berggren et al., 2010; Mattes and Milazzo,2014; Lawson et al.,2010; Little, Anthony, 2014). Studies have been conducted to test this in very different scenarios such as war and peace (Little et al. 2007; Little et al. 2014). The effect is especially pronounced when voters have low information (Lenz and Lawson, 2011). We shall leverage this finding in our experimental design to ensure the adequate presence of the Halo effect to study the interaction with information.

Studies have shown that physical appearance affects not only electoral outcomes but also other postings and rankings in politically sensitive areas. Mazur et al. (1984) and Murray (2014) have found that physical appearance can be used to predict military rankings and promotions and wartime duties respectively. The effect has also registered presence in military coups and dictatorships (Bartelson, 1997; Avril, 1999)

It has been argued that look-based preferences are formed unconsciously (Olson \& Marshuetz, 2005; van Leeuwen \& Macrae, 2004).These preferences are found to be almost uniform at least within a cultural group (Cunningham1995).Some believe that these preferences could even be universal (Berscheid \& Walster, 1974; Hatfield \& Spreche,1986 and Langlois et al., 2000).Murray (2014) in fact views the results from military data from an evolutionary lens rather than a socio-cultural lens alone.

The study of information and electoral decision making has also been undertaken from both theoretical and empirical standpoints. An early theoretical exploration of political decision-making, using a rational-choice framework is found in Downs (1957). Downs argued that the decision to vote in an election with a sizeable electorate is extremely unlikely for rational decision-makers who only seek to influence the election results. This point was also made by Condorcet in 1793, as observed in Mclean and Hewitt (1994). Responses have included the evoking of evolved altruism (Fowler, 2016) to arguing that voting is rewarding even if one's vote does not actually affect the outcome because fulfilling "civic duty" yields utility (Riker and Ordeshook, 1968). This interestingly leaves enough room for a behavioural investigation into why are people voting, and if people do not care if their vote actually affects the outcome, on what basis do they chose which candidate to vote?

This bears a direct relation to the idea of rational ignorance discussed above. People may very well choose to ignore relevant information on candidates and political affairs, and rationally so. Voters then rely on heuristics and emotions to decide their candidate of choice. This finally invites our study in this paper, investigating the interplay of the cognitive bias - the Halo Effect and information.

It is important to remember that these prejudices of attractiveness in articulated preferences not only automatically arise but also tend to remain in the light of additional candidate information. Among other factors, the above studies provided controls on partisanship and gender, showing that the presence of certain characteristics in the candidates often increases perceived competence and electoral performance in varied settings (Palmer and Peterson, 2015).

In this paper, we seek to uncover conditions under which information plays a role or does not. In particular, we provide people information either confirming or opposing their already formed look-based perceptions and analyse the differences.

\section{EXPERIMENTAL DESIGN}

In this paper, we use the method of randomized control experiments to isolate the Halo effect, the effect of information when it reinforces look-based preferences and when it contradicts look-based preferences. In a conventional RCE, the attributes of the population are either known or controlled using a control group. We randomize all attributes other than look based preferences and quantify look based preferences in a controlled group. We then compare results from two separate groups, in one of which we provide preference reinforcing information and in the other contradicting information. To minimize the effect of the complexity of information, we provide crisp and point wise information in both cases.

\section{A. Survey Design}

We designed three distinct survey forms for the three groups. For the control group, we include only one picture of each of two candidates. We explain to them in the form that they are expected to vote for the post of the mayor of a fictional city. They are asked to vote whom they find more fit to be the mayor of the city-based solely on looks. Do note, that we did not ask them to merely choose the one they find more "attractive", but the one they find more fit for the political post. We are cognizant of the fact that people may use different physical features to infer performance in different activities. Asking directly to vote for the mayor's 
post ensures that the effect of the looks on political choice only is covered.

We did not quantify the information effect separately. This was deemed unnecessary for our purpose as we seek to understand what information adds to look based preferences and not independent of it.

For the second group, we provide the same pictures again but, in this form, they each accompany a distinct box of information about the candidates' educational qualifications, achievements and past performance.

Note that, with these two forms only, we are still not able to assess whether the information reinforces look based preferences or contradicts them.

For the third group, we again provide the same pictures and the same boxes of information, but the boxes of information are switched with each other.

By comparing the groups, we can assess the effect of information in the manner outlined below.

\section{B. Isolation of Effects}

Let $L_{1}, L_{2}$ capture the percentages of the vote based solely on looks. Regarding the information effects, we can consider them to be independent of look-based preferences or dependent on them. If we assume them to be independent and let $I_{1}, I_{2}$ represent the change in vote share due to the additional information, the following shall be the interpretation of the results.

TABLE I INTERPRETATION OF GROUP-WISE DATA ASSUMING INDEPENDENT INFORMATION EFFECTS

\begin{tabular}{|c|c|c|c|}
\hline & $\begin{array}{c}\text { Group I } \\
\text { (Control) }\end{array}$ & Group II & Group III \\
\hline Candidate I & $L_{1}$ & $L_{1}+I_{1}$ & $L_{1}+I_{2}$ \\
\hline $\begin{array}{c}\text { Candidate } \\
\text { II }\end{array}$ & $L_{2}$ & $L_{2}+I_{2}$ & $L_{2}+I_{1}$ \\
\hline
\end{tabular}

To find $I_{1}$ and $I_{2}$ we simply subtract vote shares of Candidate I in group I from group II and group I from group III respectively to get

$I_{1}=\left(L_{1}+I_{1}\right)-L_{1}$

$I_{2}=\left(L_{1}+I_{2}\right)-L_{1}$

Similarly, for Candidate II we get the following equations

$I_{1}=\left(L_{2}+I_{1}\right)-L_{2}$

$I_{2}=\left(L_{2}+I_{2}\right)-L_{2}$

Because all the entries in the table are vote shares, therefore,
$L_{1}+L_{2}=1$

$L_{1}+I_{1}+L_{2}+I_{2}=1$

$\Rightarrow I_{1}=-I_{2}$

Because of equation (7), if we find an $I_{1}$ significantly not equal to 0 , then $I_{2}$ shall also be not equal to 0 with significance. Furthermore, the signs are expected to be opposite. Because of this, conditional on this hypothesis, if we see a significant result in group II, we shall also see significant results in group III and in opposite directions.

On the other hand, we may drop this assumption that information effects are independent of look based preferences. In this paper, from the numerous possibilities, we hypothesize as a second hypothesis that the information effect depends on whether the additional information reinforces the look-based preferences or contradicts them.

Here then, $I_{1}, I_{2}$ are not unknown constants but unknown functions from the set $\{0,1\}$ to $R$, where 1 indicates that the information reinforces the look based preferences and 0 indicates contradiction with look based preferences. If $x \in\{0,1\}$, then the group data indicates the following:

TABLE II INTERPRETATION OF GROUP-WISE DATA ASSUMING DEPENDENT INFORMATION EFFECTS

\begin{tabular}{|c|c|c|c|}
\hline & $\begin{array}{c}\text { Group I } \\
\text { (Control) }\end{array}$ & Group II & Group III \\
\hline Candidate I & $L_{1}$ & $L_{1}+I_{1}(x)$ & $\begin{array}{l}L_{1}+I_{2}(1 \\
-x)\end{array}$ \\
\hline $\begin{array}{c}\text { Candidate } \\
\text { II }\end{array}$ & $L_{2}$ & $L_{2}+I_{2}(x)$ & $\begin{array}{l}L_{2}+I_{1}(1 \\
-x)\end{array}$ \\
\hline
\end{tabular}

Here again, as the table entries are vote shares, we have,

$L_{1}+L_{2}=1$

$L_{1}+I_{1}(x)+L_{2}+I_{2}(x)=1$

$L_{1}+I_{1}(1-x)+L_{2}+I_{2}(1-x)=1$

Note that in this case $I_{1}(x)$ and $I_{2}(1-x)$, which are the information effect for candidate I in group II and III respectively are independent of each other.

It can be shown that $I_{1}(x)=-I_{2}(x)$ and $I_{1}(1-x)=$ $-I_{2}(1-x)$, but this is not only mathematically trivial, given that the vote shares add up to 1 , but are also tautologically true regardless of the hypothesis chosen and thus empirically unfalsifiable. In this sense, this hypothesis may appear operationally meaningless. This serves as a framework to interpret results only. A finding from the result can be used to augment this hypothesis and thus, 
render it operationally meaningful. We seek to do this too in this paper.

The key takeaway for our empirical purpose here from this hypothesis is that significant results in group II do not imply significant results in group III.

We can measure $I_{1}(x)$ by subtracting Candidate I's vote share in group I from that in group II, and $I_{2}(1-x)$ by subtracting the vote share in group I from group III. $I_{1}(1-x)$ And $I_{2}(x)$ can then be deduced simply by using the negative relations outlined in the previous paragraph.

\section{Sample and Sample Size}

We had access to a list of students from various colleges of the University of Delhi. We further gained access to contacts of students and working professionals from various parts of India. From this list, we selected 252 people at random. To each of these 252 people, we sent one and only one of the three forms at random. Thus, who among the 252 people received which form was completely random. We had a total of 146 responses.

Tackling Selection Bias: The questions were not revealed to the respondents before they agreed to respond. Thus, they could not have decided to respond based on which form they received. Their decisions were completely independent and thus, the bias of self- selection was not possible. Again, there could have been differences between the characteristics of people who chose to respond and those who did not, but this bias did not penetrate our results because we did not compare the results of the people who selected against those who did not. We only compared subgroups of the responding population.

Within the group of people who did choose to respond, the allocation of the forms was completely random and independent of the decisions made by them. This has increased our confidence in the fact that the results are largely unbiased.

\section{RESULTS}

\section{A. Descriptive Statistics}

We treat each vote as a Bernoulli random variable assigning a value of 1 for a vote to Candidate I and 0 for a vote to Candidate II. Note, however, that these variables are different from the preference reinforcing-contradicting variable defined before, and represent only voting choices, not group preferences. The mean of each group is simply the vote share of Candidate I. The statistics for Candidate II can be easily deduced.

The following are the descriptive statistics for the three groups:

Group I (Control Group)
TABLE III DESCRIPTIVE STATISTICS FOR GROUP I

\begin{tabular}{|c|c|}
\hline Sample Mean & 0.75 \\
\hline Sample Standard Deviation & 0.43 \\
\hline Total Number of votes & 57 \\
\hline
\end{tabular}

Candidate I, with $75 \%$ of the 57 votes is the winner. We infer that looks suggest Candidate I to be a better choice than Candidate II.

Group II

TABLE IV DESCRIPTIVE STATISTICS FOR GROUP II

\begin{tabular}{|c|c|}
\hline Sample Mean & 0.63 \\
\hline Sample Standard Deviation & 0.50 \\
\hline Total Number of votes & 32 \\
\hline
\end{tabular}

Candidate I am the winner again with $63 \%$ of the votes. Although the margin appears to have reduced, we shall test for its significance later.

Group III

TABLE V DESCRIPTIVE STATISTICS FOR GROUP III

\begin{tabular}{|c|c|}
\hline Sample Mean & 0.54 \\
\hline $\begin{array}{c}\text { Sample Standard } \\
\text { Deviation }\end{array}$ & 0.50 \\
\hline Total Number of votes & 52 \\
\hline
\end{tabular}

Candidate I am the winner for this group too, with an even lower margin. We shall test for the significance of this drop too later.

Although we have not yet tested for the significance, we can comment on the prospects of the information effects being independent of the Halo effect even now.

This hypothesis predicted that the signs of differences in victory margins of group II and III from the control group would be opposite. But, because the margins are lower for both group II and III, this hypothesis can be defended only if the drops in both the groups are statistically not significant.

\section{INTERPRETATION OF RESULTS}

To estimate the information effects, we find the difference of the mean of group I from the means of group II and group III, respectively. We also check for significance in both the cases, with a level of significance of $10 \%$. We assumed equal variances as the groups are randomly divided from a single population. 
TABLE VI T-TEST - GROUP I V/S GROUP II

\begin{tabular}{|l|c|c|}
\hline & Group I & Group II \\
\hline Mean & 0.75 & 0.63 \\
\hline Variance & 0.19 & 0.24 \\
\hline Observations & 57 & 32 \\
\hline Pooled Variance & \multicolumn{2}{|c|}{0.22} \\
\hline $\begin{array}{l}\text { Hypothesized Mean } \\
\text { Difference }\end{array}$ & \multicolumn{2}{|c|}{0} \\
\hline Degrees of freedom & \multicolumn{2}{|c|}{87} \\
\hline t Statistics & \multicolumn{2}{|c|}{1.29} \\
\hline P(T<=t) one-tail & \multicolumn{2}{|c|}{0.10} \\
\hline t Critical one-tail & \multicolumn{2}{|c|}{1.30} \\
\hline P(T<=t) two-tail & \multicolumn{2}{|c|}{0.20} \\
\hline t Critical two-tail & \multicolumn{2}{|c|}{1.66} \\
\hline
\end{tabular}

TABLE VII T-TEST - GROUP I V/S GROUP III

\begin{tabular}{|l|c|c|}
\hline & Group I & Group III \\
\hline Mean & 0.75 & 0.54 \\
\hline Variance & 0.19 & 0.25 \\
\hline Observations & 57.00 & 52.00 \\
\hline Pooled Variance & \multicolumn{2}{|c|}{0.22} \\
\hline $\begin{array}{l}\text { Hypothesized } \\
\text { Mean Difference }\end{array}$ & \multicolumn{2}{|c|}{0.00} \\
\hline $\begin{array}{l}\text { Degrees of } \\
\text { freedom }\end{array}$ & \multicolumn{2}{|c|}{107.00} \\
\hline t Statistics & \multicolumn{2}{|c|}{2.40} \\
\hline -P(T<=t) one-tail & \multicolumn{2}{|c|}{0.01} \\
\hline t Critical one-tail & \multicolumn{2}{|c|}{1.29} \\
\hline P(T<=t) two-tail & \multicolumn{2}{|c|}{0.02} \\
\hline t Critical two-tail & \multicolumn{2}{|c|}{1.66} \\
\hline
\end{tabular}

The observed difference in means of group I and group II is 0.12 . With a pooled sample variance of 0.22 , the difference of means is not significantly different from 0 .

The observed difference in the mean of group I and group III is 0.21 . With a pooled sample variance of 0.22 , the difference of mean is significantly different from 0 .

The direction of Information Effect: We observe by comparing group I and group III that the mean of group III is not only significantly different from the mean of group I but also significantly less than it, as observed from the onetailed t-test with the same level of significance of $10 \%$. We thus believe that the information contradicted the preferences based on looks in this case.

\section{A DISCUSSION ON THE HYPOTHESES}

We commented earlier that the hypothesis that the information effects are independent of the look-based preferences predicts, $I_{1}=-I_{2}$. We further commented later on that we shall expect significant results for both group II and group III or in none of them but not in one group but not the other. Contrary to the expectation we found a significantly negative information effect for group III while the information effect in group II is not significantly different from 0 . For clarity, we directly test the prediction of this hypothesis. We observe that according to this hypothesis the effect of information on Candidate I in group II is equal to the negative of the effect in group III. Therefore, adding these is predicted to yield zero. We get the estimates for each from tables 6 and 7 respectively. The respective estimates are 0.12 and 0.21 . The estimated variances are 0.011 and 0.008 . Because the degrees of freedom are substantially higher than 30 in each case, we assume normality. Accordingly, the sum of these variables would also be normal. The following are the estimated values:

\section{TABLE VIII TEST OF SIGNIFICANCE ASSUMING $\mathrm{I}_{1}+\mathrm{I}_{2}=0$}

\begin{tabular}{|c|c|}
\hline Mean & 0.33 \\
\hline Variance & 0.019 \\
\hline Z -value & 2.39 \\
\hline P-value & 0.017 \\
\hline
\end{tabular}

The estimated mean is significantly different from 0 at a significance level of $10 \%$. Thus, the hypothesis is rejected. This brings us to the second hypothesis. The following are the estimated values for this hypothesis:

\section{TABLE IX ESTIMATES OF VARIABLES ASSUMING DEPENDENT INFORMATION EFFECTS}

\begin{tabular}{|c|c|c|}
\hline$I_{1}(1)$ & -0.12 & Insignificant \\
\hline$I_{1}(0)$ & -0.21 & Significant \\
\hline$I_{2}(1)$ & 0.12 & Insignificant \\
\hline$I_{2}(0)$ & 0.21 & Significant \\
\hline
\end{tabular}

We observe that the information effect is significantly nonzero when the information contradicts the look-based preferences while they are not significantly non-zero when they reaffirm look-based preferences. This may invite a discussion on how people choose to use their mental faculty to understand the world around them. An idea that seems relevant here is the Identity-Protective Cognition Thesis (ICT). A paper supporting this thesis, against an alternate hypothesis, for instance, found that people use their skills of numeracy selectively based on whether the numerical data presented reaffirms or contradicts the beliefs they already had. When the numerical data reaffirmed their political beliefs at a superficial level, even people with high numeracy skills chose not to use their skills for proper inspection of the data. On the other hand, when the data contradicted their beliefs even at a superficial level, people did choose to investigate further (Kahan et al, 2013). 
In this paper, numerical data has not been prepared, but pictorial and verbal data, two points may be noted from the results of this paper, concerning the ICT:

1. The result that the information effect was insignificant in group II where the verbal information reinforced the look-based preferences may indicate that respondents chose not to thoroughly examine the verbal data, once it superficially supported the look-based preferences. This may indicate that the ICT holds even for verbal data following pictorial data. This may also lead to the question of whether some forms of data are prioritized higher than others when it comes to the intuitive analysis of data. This paper, however, does not test this claim, or even the ICT directly. These are mere comments regarding the possibilities in light of the data analysed here and may serve to inspire future research.

2. The second point speculates the power of first impressions. In Kahan et al. (2013), strongly held and long formed beliefs about politics and society confronted new numerical data. If the ICT holds, even in this paper involving pictorial and verbal data, as contemplated by the authors, then it is astonishing that beliefs and preferences about the candidates formed merely by looking at one picture each of the candidates can induce such strong effects, to prompt respondents to ignore new data in certain cases, as if the look based preferences are sacrosanct beliefs. The refusal to investigate further data thoroughly even though the data presented earlier was scarce and pictorial, may indicate that the issue is grave and widespread.

Seeing these results in the light of the Halo effect, on the other hand, provides us with an altogether new approach to explain the data, but given the striking analogy (or even homology in our view) to the ICT results, to also explain other ICT results from a new approach. Van Leeuwen \& Macrae (2004) have argued that the Halo effect reflects the inability of the voters to differentiate between different characteristics being evaluated, although sometimes subconsciously. In this light, when the additional information reinforces look- based preferences, it simply makes the two sets of information consistent, without adding much new. On the other hand, when the contradiction occurs, people integrate the two sets of information without a proper grasp of which set of information to use for which purpose.

\section{CONCLUSION}

The interaction of the Halo effect and additional information, at least in the political domain is complex. How additional information is treated or analysed depends crucially on beliefs held earlier. While this has been studied before especially in cases where the pre-existing beliefs were formed in a complex manner and were deeply embedded in society, in this paper we allowed the formation of completely fresh beliefs. Furthermore, the beliefs were formed based on very scarce data- only one photograph of each candidate. It appears that even these feebly formed beliefs prompt respondents to ignore further data in certain cases.

Whether the respondents' choices are affected by the new information depended crucially on whether the new information reaffirmed or contradicted their look-based beliefs. In group II, where reaffirmation took place, the information effect was not significant. In group III on the other hand, where contradiction took place, the information effect was significant. The idea of rational ignorance suggested that a lot of information will be ignored by the voters. In some studies, the idea of selective processing of information was introduced where strongly held beliefs confronted new data. In the current paper, on the other hand, new and feebly formed beliefs confronted new data. Interestingly, even the new and feebly formed beliefs based solely on one picture each of the candidates prompted a similar effect as the strongly held beliefs.

This suggests that the reliance on the first impression is strong and this effect may relate to the repulsion to process new information, suggested by rational ignorance. In that sense, in combination with the impressive strength displayed by the feebly formed look based beliefs, it appears as if political decisions rarely reflect societal concerns. The electoral results may largely represent vague instincts .This paper helps us understand a way of forming these instincts, and also provides the astounding finding that not only is new information ignored in presence of strongly held beliefs but even in the presence of very weakly formed beliefs, based on very scarce data. This shockingly highlights the extent of ignorance, to be possibly high enough to render the electoral process very shaky.

\section{REFERENCES}

[1] Atkinson, Matthew, D., Ryan, D., Enos and Seth J. Hill. (2009). Candidate Faces and Election Outcomes: Is the Face-Vote Correlation Caused by Candidate Selection? Quarterly Journal of Political Science, 4 (3), 229-249.

[2] Avril, P. (1999). From glory to disgrace: The Haitian army, 18041994. Universal Publishers.

[3] Bartelson, J. (1997). Making Exceptions: Some Remarks on the Concept of Coup d' etat and Its History. Political Theory 25 (3), 323346.

[4] Berggren, N., Jordahl., H. and Poutvaara, P. (2017). The Right Look: Conservative Politicians Look Better and Voters Reward It. Journal of Public Economics. 146, 79-86.

[5] Berscheid, E. and Walster, E. (1974). Physical attractiveness. In Berkowitz, L. (Ed.), Advances in experimental social psychology, 7, 157-215.

[6] Cunningham, M. R., Roberts, A. R., Barbee, A. P., Druen, P. B., Wu, C. H. (1995). Their ideas of beauty are, on the whole, the same as ours: Consistency and variability in the cross-cultural perception of female physical attractiveness. Journal of Personality and Social Psychology, 68, 261-279.

[7] Downs, A. (1957). An economic theory of democracy. Harper and Row.

[8] Fowler, J. (2006). Altruism and Turnout. The Journal of Politics. 68 (3), 674-683. 
[9] Hatfield, E., Sprecher, S. (1986). Mirror, mirror: The importance of looks in everyday life. State University of New York Press.

[10] Kahan, M., Peters, E., Dawson, E. and Slovic, P. (2013). Motivated Numeracy and Enlightened Self-Government.Behavioural Public Policy. 1, 54-86. http://dx.doi.org/10.2139/ssrn.2319992.

[11] Kozlowski, S. W., Kirsch, M. P., Chao, G. T. (1986). Job knowledge, rate familiarity, conceptual similarity and halo error: An exploration. Journal of Applied Psychology. 71, 45-49.

[12] Langlois, J. H., Lisa K., Adam J. R., Andrea L., Monica H. and Monica S. (2000). Maxims or Myths of Beauty? A Meta-Analytic and Theoretical Review. Psychological Bulletin. 126, 390-423.

[13] Lawson, C., Lenz, G. S., Baker, A. and Myers, M. (2010). Looking Like a Winner: Candidate Appearance and Electoral Success in New Democracies. World Politics. 62, 561-593.

[14] Lenz, G. S. and Lawson, C. (2011). Looking the Part: Television Leads Less Informed Citizens to Vote Based on Candidates Appearance. American Journal of Political Science. 55 (3), 574-589.

[15] Little, A. C., Burriss, R. P., Jones, B. C., Roberts, S. C. (2007). Facial appearance affects voting decisions. Evolution \& Human Behavior. 28, 18-27.

[16] Little, A. C., Roberts, S. C., Jones, B. C., De Bruine, L. M. (2012). The perception of attractiveness and trustworthiness in male faces affects hypothetical voting decisions differently in wartime and peacetime scenarios. The Quarterly Journal of Experimental Psychology. 65, 2018-2032.

[17] Little, A.C. (2014) Facial appearance and leader choice in different contexts: Evidence for task contingent selection based on implicit and learned face-behaviour/face-ability associations. The Leadership Quarterly. Vol. 25, pp. 865-874.
[18] Mazur, A., Mazur, J. and Keating, C. (1984). Military Rank Attainment of a West Point Class: Effects of Cadets' Physical Features. American Journal of Sociology. 90, 125-150.

[19] Mclean, I. and Hewitt, F. (1994). Condorcet. Edward Elgar Publishing. 245-246.

[20] Murray, G. R. (2014). Evolutionary preferences for physical formidability in leaders. Association for Politics and the Life Sciences. 33, 33-53.

[21] Nisbett, R. E., \& Wilson, T. D. (1977). The halo effect: Evidence for unconscious alteration of judgments. Journal of Personality and Social Psychology. $35 \quad$ (4) 250-256. https://doi.org/10.1037/00223514.35.4.250.

[22] Olson, I. R. and Marshuetz. C. (2005). Facial attractiveness is appraised at a glance. Emotion. 5, 498-502.

[23] Palmer, C. and Peterson, R. (2015). Halo Effects and the Attractiveness Premium in Perceptions of Political Expertise. American Politics Research. 44.

[24] Surawski, M. and Ossoff, E. (2006). The Effects of Physical and Vocal Attractiveness on Impression Formation of Politicians. Current psychology. 25, 15-27.

[25] Thorndike, E. L. (1920). A constant error in psychological ratings. Journal of Applied Psychology, 4, 25-29

[26] Van-Leeuwen, M. L. And Macrae, C. N. (2004). Is beautiful always good? Implicit benefits of facial attractiveness. Social Cognition. 22, 637-649.

[27] William H., Ordeshook, P.C. (1968). A Theory of the Calculus of Voting. American Political Science Review, 62, 25-42. https://doi.org/10.1017/S000305540011562X 